\title{
Need to Promote and Disseminate the Scientific Production
}

J. Selva Andina Res. Soc. 2013; 4(2):48.

With the passage of time, advances in recent years related to scientific production, requires to university institutions, research's institutes and/or centers, governmental organizations, NGOs and independent professionals to be part of this dynamic development process.

Journal of the Selva Andina Research Society, official organ of the Scientific Society "Selva Andina Research" marks an important milestone in the development of multidisciplinary research to provide to the university professors, independent professionals, research's institutes and/or centers, governmental organizations or NGOs an open space for dissemination of research performed, especially if them resolve latent problems in health, environment, agricultural production or education among others.

It follows, arise a lot of questions. Is it possible that publications give an incentive to the professional who has published in internationally refereed and indexed journal? We consider it is necessary because in the future this will be useful to apply on different professional's activities who offer services to diverse institutions, such as public or private hospitals, institutions that are looking for provide solutions to the environmental problems, as the cases of solid waste, plastic bottles or environmental contamination by pollution.

We believe therefore that we are in the process to generate quality and useful information from many fields to improve the quality of life in society.

Currently, Journal of the Selva Andina Research Society has seven numbers, not been easy to make. We published high-level national and international research work being referenced. We believe that is time that local, national and regional institutions place confidence in the selection process of the manuscripts to be published as we have a staff of serious professionals that give quality to review and analysis.

Finally, we have to promote, disseminate, encourage and recognize research's works in the diverse knowledge fields and, logically, make them visible to the benefit of the society development.

Manuel Gregorio Loza-Murguia DIRECTOR - EDITOR EN JEFE

Presidente Ejecutivo - Honorario de la Junta Directiva Consejo Superior de Investigación en Ciencia y Biotecnología Fundación Selva Andina Research Society

La Paz - Bolivia

Tel. 591 - 67110665 -752 14458

E-mail. infoselvandina@gmail.com

E-mail. boliviamanloza@yahoo.com

2013. Journal of the Selva Andina Research Society. Bolivia. All rights reserved. 